\title{
LIQUID PHASE MASS TRANSFER IN PACKED BED REACTOR WITH COCURRENT GAS-LIQUID DOWNFLOW*
}

\author{
Tsutomu HIROSE, Mikio TODA** AND Yuji SATO \\ Department of Chemical Engineering, Kyushu University, Fukuoka
}

\begin{abstract}
Volumetric absorption coefficient $(k a)_{l g}$, specific interfacial area $a_{l g}$ and mass transfer coefficient $k_{l g}$ were measured for two-phase cocurrent flow of $\mathrm{O}_{2}$-water and $\mathrm{CO}_{2}-\mathrm{NaOH}$ systems in a column packed with glass spheres of 3 different sizes $(2.59-12.2 \mathrm{~mm})$. Values of $(\mathrm{ka})_{l g}$ observed were so high as to be that can be hardly attainable in conventional gas-liquid contactors. This is due to large $a_{l g}$ of small bubbles dispersed in liquid where $a_{l g}$ very often exceeds the geometrical surface area of packing. Values of $k_{l g}$ range from 2 to $8 \times 10^{-4} \mathrm{~m} / \mathrm{sec}$, which are comparable to that of circulating bubbles in the usual systems. The effect of superficial gas velocity on $(k a)_{l g}$ and $a_{l g}$ is much greater than that in a countercurrent packed column, while the effect of liquid velocity is approximately same. A liquid-phase energy loss $E_{l}$ per unit volume of liquid contained in a bed was newly defined as a measure of microscopic flow intensity and was used for discussion and correlation of mass transfer properties. It was found that the bubble diameter is proportional to $E_{l}^{-2 / 5}$.
\end{abstract}

\section{Introduction}

Advantages of packed column reactors with cocurrent gas-liquid flow have been pointed out by many investigators ${ }^{4,5,7,10,14,16)}$. This type of reactor may be employed in a) gas-liquid reaction with inert packing, b) gas-liquid reaction catalyzed by packing solid ${ }^{7}$, and c) solid-catalized gas reaction in inert liquid phase introduced for temperature control ${ }^{14)}$. In any case, the reactant gas must first be dissolved in liquid for the reaction to proceed. Thus, gas-liquid mass transfer is one of the most fundamental steps in determining the overall reaction rate as well as the intrinsic chemical kinetics and liquid-particle (catalyst) mass transfer, if any.

Volumetric absorption coefficient $(k a)_{l g}$, specific gas-liquid interfacial area $a_{l g}$ and mass transfer coefficient $k_{l g}$ have been used for characterizing the mass transfer performance of various gas-liquid contactors. However, surprisingly little is known about these factors for coccurrently contacting packed columns. No prediction correlations are available except those of Reiss ${ }^{10)}$ for $(k a)_{l g}$ and of Gianetto, Baldi and Specchia $^{5)}$ for $a_{l g}$. As for $k_{l g}$, not even the order of magnitude has been reported yet. Thus, much more investigation is desired to understand the mass transfer behaviour.

\footnotetext{
* Received on July 23, 1973

Presented at the First Pacific Chem. Eng. Congress, Kyoto, Japan, Oct. 10-14, 1972

** Daicel Ltd., Himeji

$\overline{\mathbf{T}} 812$ 福岡市東区箱崎

九州大学工学部化学機械工学科 広瀬 勉
}

From this point of view, the purpose of the present article is to present new data and correlations of gas-liquid mass transfer properties and to discuss the results in the light of the fluid flow behaviour reported previously ${ }^{12,13)}$.

\section{Experiments}

A schematic diagram of the experimental apparatus is shown in Fig. 1. Since no appreciable effect of column diameter was found in the fluid flow characteristics $^{12,13)}$, one column of $65.8 \mathrm{~mm}^{\phi}$ I.D. and $0.25 \mathrm{~m}$ long was used. The column height was made rather short to prevent the attainment of equilibrium between phases in the exit stream. The range of variables investigated is summarized in Table 1. The details of the distributor head and void fraction of bed were reported previously ${ }^{12}$.

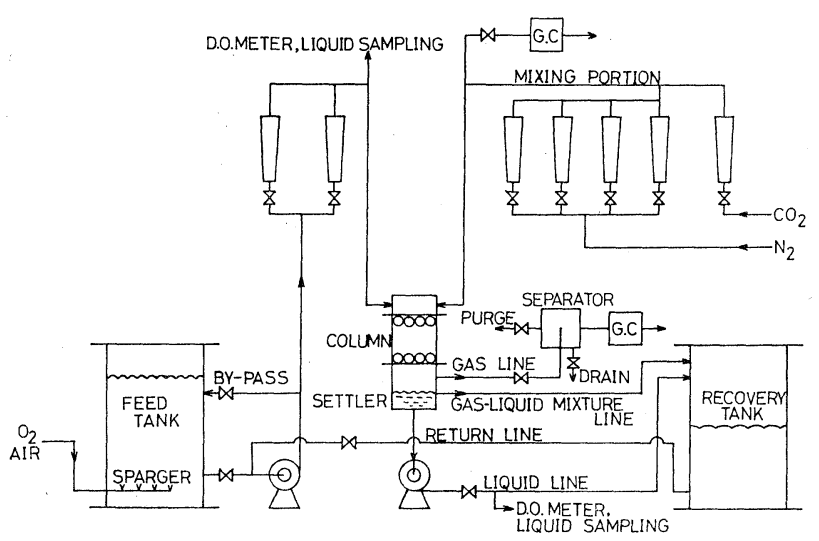

Fig. 1 Schematic diagram of apparatus for mass transfer measurements 
Table 1 Range of variables investigated

\begin{tabular}{|c|c|c|c|c|c|c|c|c|c|}
\hline \multirow[b]{2}{*}{ Measurement } & \multirow[b]{2}{*}{ Solute } & \multirow[b]{2}{*}{ Liquid } & \multicolumn{2}{|c|}{ Column } & \multicolumn{2}{|c|}{ Packing } & \multicolumn{2}{|c|}{ Superficial velocity } & \multirow[b]{2}{*}{$\begin{array}{l}\text { Temp. } \\
t\left[{ }^{\circ} \mathrm{C}\right]\end{array}$} \\
\hline & & & $\begin{array}{c}\text { Dia. } \\
D \times 10^{3}[\mathrm{~m}]\end{array}$ & $\begin{array}{c}\text { Height } \\
h[\mathrm{~m}]\end{array}$ & $\begin{array}{l}\text { Dia. } \\
d \times 10^{3}[\mathrm{~m}]\end{array}$ & $\begin{array}{l}\text { Void } \\
\varepsilon[-]\end{array}$ & $\begin{array}{c}\mathrm{Gas} \\
U_{g}[\mathrm{~m} / \mathrm{sec}]\end{array}$ & $\begin{array}{c}\text { Liquid } \\
U_{l}[\mathrm{~m} / \mathrm{sec}]\end{array}$ & \\
\hline $\begin{array}{l}\text { Volumetric absorption } \\
\text { coefficient }\end{array}$ & $\mathrm{O}_{2}$ & $\mathrm{H}_{2} \mathrm{O}$ & 65.8 & 0.25 & $\begin{array}{c}2.59 \\
5.61 \\
8.01 \\
12.2\end{array}$ & $\begin{array}{l}0.370 \\
0.391 \\
0.408 \\
0.438\end{array}$ & $0.05-1.0$ & $0.01-0.2$ & $\sim 15$ \\
\hline $\begin{array}{l}\text { Specific interfacial } \\
\text { area }\end{array}$ & $\mathrm{CO}_{2}$ & $\begin{array}{c}0.1 \sim 1 \mathrm{~N} \\
\mathrm{NaOH}\end{array}$ & 65.8 & 0.25 & $\begin{array}{c}2.59 \\
5.61 \\
12.2\end{array}$ & $\begin{array}{l}0.370 \\
0.391 \\
0.438\end{array}$ & $0.01-1.0$ & $0.01-0.1$ & 30 \\
\hline
\end{tabular}

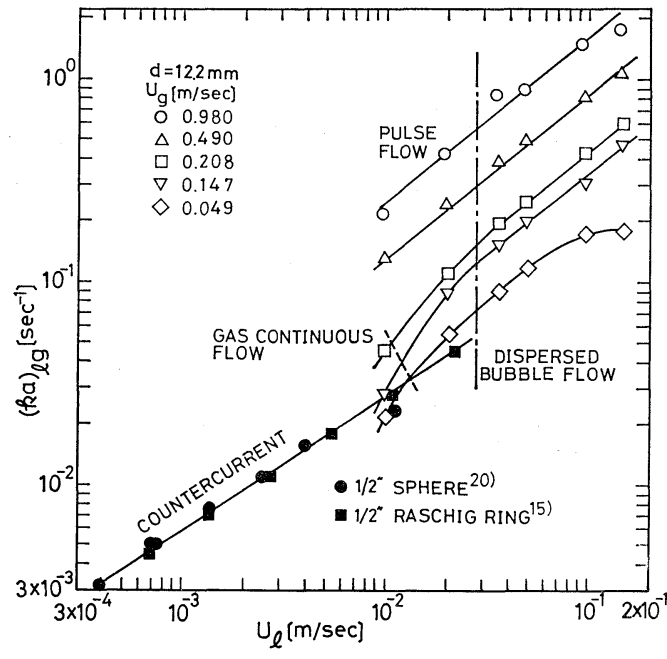

Fig. 2 Typical examples of results for volumetric absorption coefficient

Volumetric absorption coefficient $(k a)_{l g}$ was determined through desorption mass transfer of dissolved oxygen from the presaturated water into the nitrogen stream. An oxygen analyzer (ToshibaBeckman Co., Model 777) was immersed in the entrance stream to detect the inlet concentration $C_{l}^{\circ}$. Gas-liquid dispersion issuing from the column was separated in the bottom and part of the liquid was led to a liquid line, where another oxygen analyzer was set to detect the outlet concentration $C_{l 1}$. Since unfortunately no information is available on the longitudinal dispersion, the present data were analyzed tentatively in terms of plug flow and volumetric absorption coefficient $(k a)_{l g}$ was calculated from the equation

$$
(k a)_{l g}=\left(U_{l} / h\right) \ln \left(C_{l}^{\circ} / C_{l 1}\right)
$$

Oxygen partial pressure in the bulk gas phase was practically zero due to the low solubility. The gasphase resistance to mass transfer was neglected. Desorption was preferred to absorption since the latter case was complicated by the longitudinal variation in gas-phase concentration of oxygen due to pressure drop through the bed.

Specific interfacial area $a_{l g}$ was measured using a diffusion-limited chemical absorption of carbon dioxide into aqueous sodium hydroxide. Carbon dioxide was diluted with nitrogen so that the total flow rate

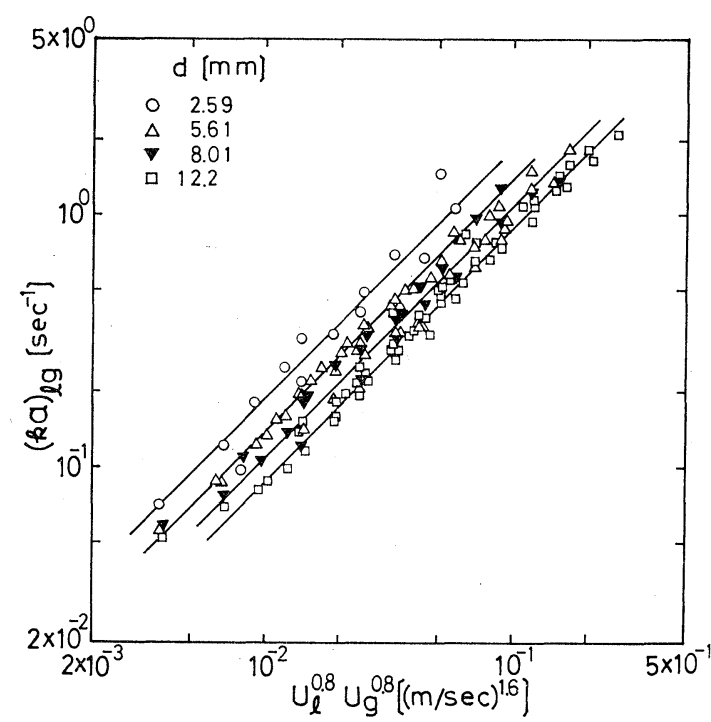

Fig. 3 Correlation of volumetric absorption coefficient in terms of operating parameters

of $\mathrm{CO}_{2}$ and $\mathrm{N}_{2}$ did not change more than $30 \%$ between entrance and exit. Feed gas and liquid were sampled from the entrance streams. Outlet liquid was sampled from the outlet liquid line while outlet gas sample was taken after the removal of entrainment drops. Gas $\left(\mathrm{CO}_{2}\right)$ and liquid $(\mathrm{NaOH})$, respectively, were analyzed by gas chromatography and by Warder's titration. The rate of gas absorption $N$ was determined from the difference of the concentrations of both $\mathrm{NaOH}$ in solution and $\mathrm{CO}_{2}$ in bulk gas between the entrance and exit streams, the material balance being satisfactorily checked.

Under the condition of a fast pseudo first-order reaction the absorption rate per unit volume of bed $N$ is given by

$$
N=a_{l g} \lambda \bar{C}_{g} \sqrt{\mathscr{D} k_{r} \bar{C}_{b}}
$$

To evaluate $a_{l g}$, arithmetic and logarithmic mean concentrations, respectively, between entrance and exit were used for $\bar{C}_{b}$ and $\bar{C}_{g}$. The intrinsic reaction rate constant $k_{r}$, the diffusion coefficient $\mathscr{D}$ and solubility $\lambda$, respectively, were estimated for the above determined mean concentration according to Yoshida and Miura ${ }^{22)}$, Wilke ${ }^{19)}$, and van Krevelen and Hofftijzer $^{17)}$.

The mass transfer coefficient $k_{l g}$ for oxygen was determined by dividing $(k a)_{l g}$ by $a_{l g}$ obtained above. 


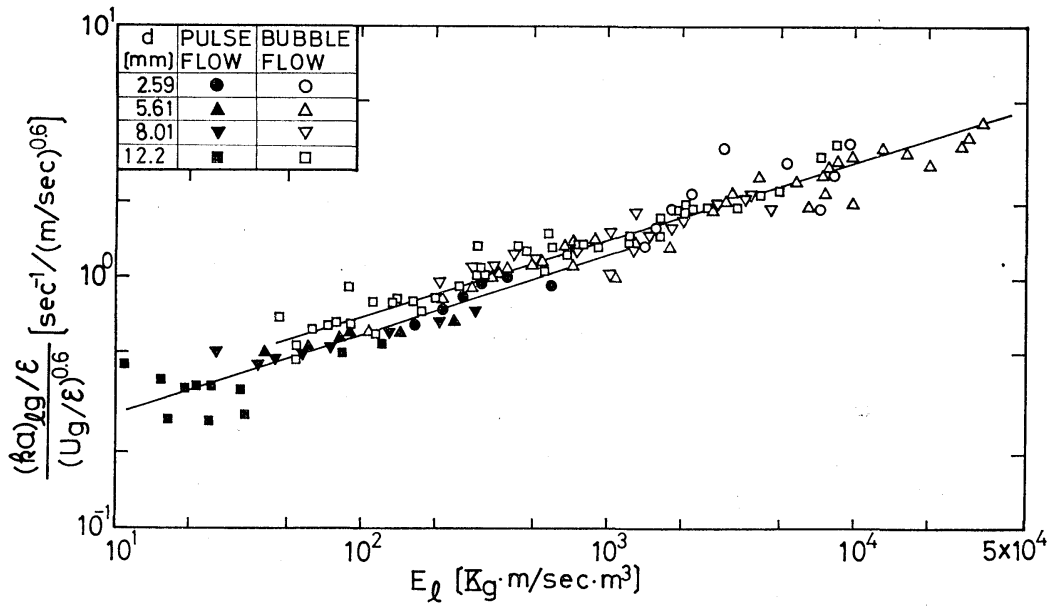

Fig. 4 Correlation of volumetric absorption coefficient in terms of liquid-phase energy loss
The requirements for a diffusion-limited first-order reaction were examined using the resultant $k_{l g}$.

\section{Volumetric Absorption Coefficient}

Some experimental results of the volumetric absorption coefficient $(k a)_{l g}$ are shown in Fig. 2 together with available data obtained for the corresponding systems in countercurrent flow ${ }^{15,20)}$. The values of $(k a)_{l g}$ at low gas flow rate fall on a line extrapolated from countercurrent data. Increase in gas flow rate increases these values up to ten times their values at low gas flow rate.

This strong dependence on gas flow rate is quite a different behaviour from that in countercurrent flow, where $(k a)_{l g}$ is known to be independent of gas flow rate lower than the loading point. At high flow rate of gas and liquid, some values of $(k a)_{l g}$ exceed $1 \mathrm{sec}^{-1}$, which can hardly be attained in other types of gas-liquid contactors such as an agitated vessel or a bubble column.

Most of the data were taken under the pulse or dispersed bubble flow regime. At liquid velocity lower than $1 \mathrm{~cm} / \mathrm{sec}$ the flow approached gas continuous flow, in which it has been reported that $(k a)_{l g}$ decreases rapidly, probably due to the poor distribution of liquid ${ }^{5)}$. Thus pulse and dispersed bubble flow, containing gas-liquid dispersion, seem preferable from a mass-transfer point of view.

The volumetric absorption coefficient $(k a)_{l g}$ is proportional to $U_{l}^{0.8}$, as shown in Fig. 2, and is observed to decrease with increasing packing diameter $d$ as shown in Fig. 3. Thus the present data are correlated by

$$
(k a)_{l g}=1.0 d^{-0.5} U_{l}^{0.8} U_{g}^{0.8}
$$

in terms of flow rates and packing size.

Mass transfer properties in two-phase dispersion have sometimes been related to energy dissipation, in which various geometrical factors may be excluded from the resulting correlations. For example, such treatment was applied to agitated gas-liquid contactors by Cooper, Fernstrom and Miller ${ }^{3)}$ and Yoshida, Ikeda, Imagawa and Miura ${ }^{21)}$, to two-phase tubular contactors by Gregory and Scott ${ }^{6)}$ and to twophase flow in packed beds by Reiss ${ }^{10)}$.

When gas flows with a high velocity, as in twophase flow in a packed bed, a considerable amount of energy dissipation occurs in the gas phase as well as in the liquid phase. However, the energy dissipation in the liquid phase is of primary importance for the present system, the liquid-phase resistance to mass transfer being controlling. Thus, the liquidphase energy loss per unit volume of liquid contained in the bed is defined in this work as

$$
E_{l}=\left(\Delta P_{l g} / \Delta h\right) U_{l} / \varepsilon R_{l}
$$

Strictly speaking, the above-defined $E_{l}$ is the power given to liquid by an external machine (i.e. pump) and is not always equal to the energy dissipated in liquid phase when energy is exchanged between gas and liquid phases. However, it may be a good measure to characterize the latter quantity.

When the energy loss $E_{l}$ and the interstitial gas velocity $U_{g} / \varepsilon$ are chosen as two correlating parameters, the correlation shown in Fig. 4 is obtained. It is explicitly independent of packing size although the packing diameter affects $(k a)_{l g}$ by changing the energy loss $E_{l}$. The best-fit line to the present data is given by

$$
(k a)_{l g} / \varepsilon=0.163\left(U_{g} / \varepsilon\right)^{0.6} E_{l}^{0.31}
$$

for the dispersed bubble flow regime and

$$
(k a)_{l g} / \varepsilon=0.135\left(U_{g} / \varepsilon\right)^{0.6} E_{l}^{0.31}
$$

for the pulse flow regime. $\Delta P_{l g}$ and $R_{l}$ necessary for calculation of $E_{l}$ are evaluated by previously reported correlations $^{12)}$.

$$
\begin{aligned}
& \phi_{l}=\sqrt{\Delta P_{l g} / \Delta P_{l}}=1.30+1.85 \chi^{-0.85} \\
& R_{l}=0.04 a_{s}^{1 / 3} \chi^{0.22}
\end{aligned}
$$

The value of $(k a)_{l g}$ in pulse flow is a little lower than that in dispersed bubble flow since the bubble dispersion does not occupy the whole bed, unlike the case in the latter regime. 


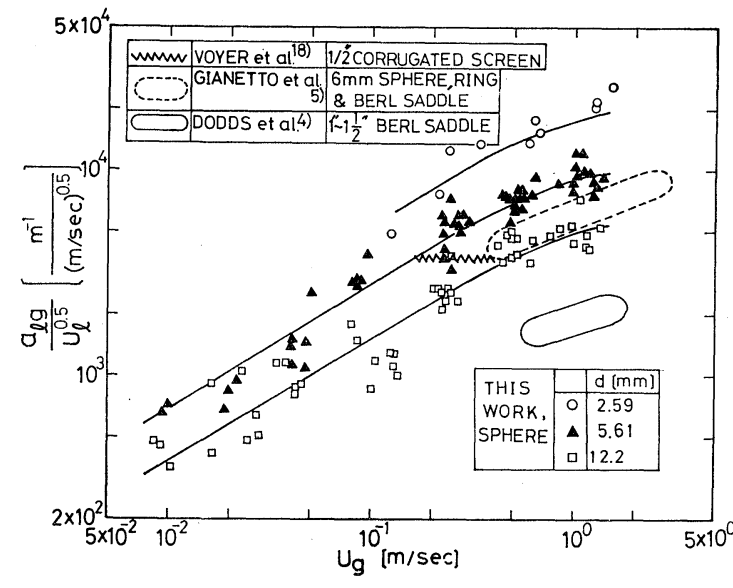

Fig. 5 Correlation of specific interfacial area in terms of operating parameters

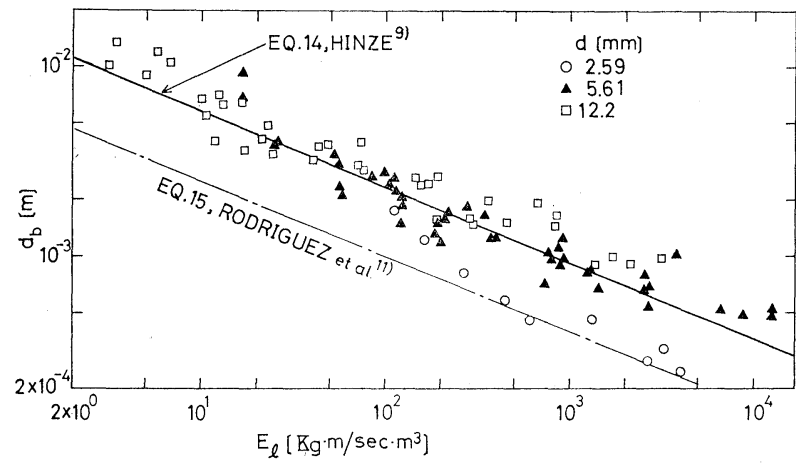

Fig. 6 Bubble diameter calculated from gas holdup and specific interfacial area

Reiss $^{10)}$ has proposed a correlation

$$
(k a)_{l g}=0.0542\left(U_{l} \Delta P_{l q} / \Delta h\right)
$$

for spheres and rings, which is independent of gas flow rate as well as of packing size. The present data included in his reported range of gas velocity $\left(U_{l}>0.5 \mathrm{~m} / \mathrm{sec}\right)$ are consistent with the Reiss ${ }^{10)}$ equation. However, to cover the data at lower gas velocity, the gas velocity must be included in the correlation.

\section{Specific Interfacial Area}

The specific interfacial area $a_{l g}$ was found to be proportional to the square root of liquid flow rate $U_{l}$. Its dependence on packing size and gas flow rate are shown in Fig. 5. The values of $a_{l g}$ decrease with packing diameter to 0.8 power and increase with gas flow rate to 0.6 power till they tend to flatten at high gas flow rate as shown in Fig. 5. An empirical equation is sought as

$$
a_{l g}=175 d^{-0.8} U_{l}^{0.5} U_{g}^{0.6}, \quad U_{g}<0.6 \mathrm{~m} / \mathrm{sec}
$$

The gas-liquid interfacial area very often exceeds the geometrical surface area of packings, indicating a large contribution of small bubbles in pulse flow and dispersed bubble flow regimes.

Some available results are also reproduced in the figure for comparison. Data of Voyer and Miller ${ }^{18)}$ and Gianetto, Baldi and Specchia ${ }^{5)}$ were read directly from their figures. Those of Dodds, Stutzman, Sollami and $\mathrm{McCarter}^{4)}$ were evaluated from the tabulated absorption rates of $\mathrm{CO}_{2}$ into $2 \mathrm{~N}-\mathrm{NaOH}$ solution according to Eq. (2) by the present authors. The density of gas, if necesssary, was taken as that of air under atmospheric pressure. The agreement between the present data and these results seems reasonable in spite of the different geometries and sizes of packing. Results of Dodds et al. ${ }^{4)}$ and Gianetto et $a l . .^{5}$ show the same dependence on gas flow rate as do the present data, but lower dependence on liquid flow rate, i.e. 0.3-0.4 power instead of 0.5.

The mechanism of the dispersion of bubbles and drops has been interpreted in the light of turbulence theory ${ }^{9}$. It is assumed that the diameter of a bubble or drop is controlled by a balance of the kinetic energy of turbulence and the surface energy, i.e. there exists a critical Weber number

$$
W e_{\text {crit }}=\rho_{c} \bar{v}^{2} d_{b} / \sigma
$$

In Eq. (11), $\bar{v}^{2}$ is the average value of the squares of velocity differences over a distance equal to the bubble diameter $d_{b}$ and is given by

$$
\bar{v}^{2} \propto\left(E_{l} g_{c} d_{b} / \rho_{c}\right)^{2 / 3}
$$

for an isotropic homogeneous turbulence where the Kolmogoroff energy distribution law applies. Substituting Eq. (12) into Eq. (11) gives

$$
d_{b}=\alpha \rho_{c}^{-1 / 5} \sigma^{3 / 5} E_{l}^{-2 / 5} g_{c}{ }^{1 / 5}
$$

Hinze $^{9)}$ determined $\alpha=0.725$ for the maximum drop diameter in two coaxial cylinders, and Rodriguez, Groze and Engle ${ }^{11)}$ gave $\alpha=0.286$ for the average drop size in agitated vessels.

For the present system $\left(\rho_{c}=10^{3} \mathrm{~kg} / \mathrm{m}^{3}, \sigma=7 \times 10^{-3}\right.$ $\mathrm{Kg} / \mathrm{m}$ ) Eq. (13) reduces to

$$
\begin{aligned}
& d_{b}=1.46 \times 10^{-2} E_{l}-2 / 5 \quad\left(\alpha=0.725, \text { Hinze }^{9}\right) \\
& d_{b}=0.58 \times 10^{-2} E_{l}-2 / 5 \\
&\left(\alpha=0.286, \text { Rodriguez et al. }{ }^{11)}\right)
\end{aligned}
$$

Assuming that all the gas holdup is in the form of spherical bubbles, the bubble diameter was calculated from the equation

$$
d_{b}=6\left(1-R_{l}\right) \varepsilon / a_{l g}
$$

where liquid holdup $R_{l}$ was evaluated by Eq. (8). The results are shown in Fig. 6 and compared with Eqs. (14) and (15) for the drop dispersion in the different apparatuses. Data for $\chi>10$ are not included in Fig. 6 because the values of $R_{l}$ are close to unity for large $\chi$ and a large error is produced in evaluating the term $\left(1-R_{l}\right)$ in Eq. (16). As shown in Fig. 6, the bubble diameter in the dispersion in packed beds under two-phase flow again follows the $-2 / 5$ power law of the energy loss in liquid phase. In particular, the numerical agreement with Hinze's equation, Eq. (14), is interesting. 
It is somewhat unreasonable that the calculated bubble diameter is sometimes large than the interstitial void or the packing diameter. This is interpreted by the fact that two-phase flow is in or close to gas continuous flow at the lowest liquid flow rate $\left(U_{l}=0.122 \mathrm{~cm} / \mathrm{sec}\right)$, for which the equivalent bubble diameter becomes very large. When data in this region are excluded, it reduces to the more reasonable result that $d_{b} / d$ is smaller than $1 / 2$.

When $d_{b}$ is proportional to $E_{l}^{-2 / 5}$, Eq. (16) is rewritten as follows, and finally the interfacial area $a_{l g}$ is related to a two-phase parameter $\chi$.

$$
a_{l g} E_{l}^{-2 / 5} \propto \varepsilon\left(1-R_{l}\right)=\psi(\chi)
$$

The present results are plotted in this manner in Fig. 7. Data of Gianetto, Baldi and Specchia ${ }^{5)}$ and Dodds, Stutzman, Sollami and McCarter ${ }^{4)}$ fall within a dotted circle. In spite of the wide scatter the data for different geometries and sizes of packings follow a relation of the type of Eq. (17). A sharp decrease of $a_{l g} / E_{l}^{2 / 5}$ for $\chi>5$ is due to the corresponding decrease of gas holdup, $1-R_{l}$.

\section{Mass Transfer Coefficient}

The mass transfer coefficient $k_{l g}$ for oxygen-water system was separated from the volumetric absorption coefficient $(k a)_{l g}$ by dividing by interfacial area $a_{l g}$, based on an assumption that $a_{l g}$ for water is equal to that for $\mathrm{NaOH}$ solution at the same flow rates of gas and liquid despite some difference in liquid properties. The $k_{l g}$ thus determined for about $15^{\circ} \mathrm{C}$ (experimental temperature) ranges from $2 \times 10^{-4}$ to $8 \times 10^{-4} \mathrm{~m} / \mathrm{sec}$. This range of $k_{l g}$ is consistent in order of magnitude with that for circulating bubbles in free rise ${ }^{2)}$, in bubble columns ${ }^{1)}$ and agitated gasliquid contactors ${ }^{11}$. Thus, it is concluded that the high values of $(k a)_{l g}$ encountered in cocurrent packed columns is attributable to large interfacial area $a_{l g}$ of small dispersed bubbles, but not to the mass transfer coefficient $k_{l g}$.

Eqs. (3) and (10) for $(k a)_{l g}$ and $a_{l g}$, respectively, imply $k_{l g}$ to be proportional to $U_{l}^{0.3} . \quad k_{l g} / U_{l}^{0.3}$ is plotted against the gas velocity $U_{g}$ in Fig. 8, where it is seen that the effect of $U_{g}$ is small. $k_{l g}$ decreases slightly with increasing packing diameter. The calculated bubble diameter is smaller for smaller packing at the same flow rates. Thus, according to the mass transfer theories, $k_{l g}$ is expected to be higher for smaller packing, to which the present experimental trend is opposite. This disagreement may be explained tentatively by the fact that the relative motion between a bubble and liquid may be restricted due to narrow channels surrounded by small packings.

Substituting the root mean square fluctuation velocity $\sqrt{\overline{v^{2}}}$ given by Eq. (12) and the bubble diameter

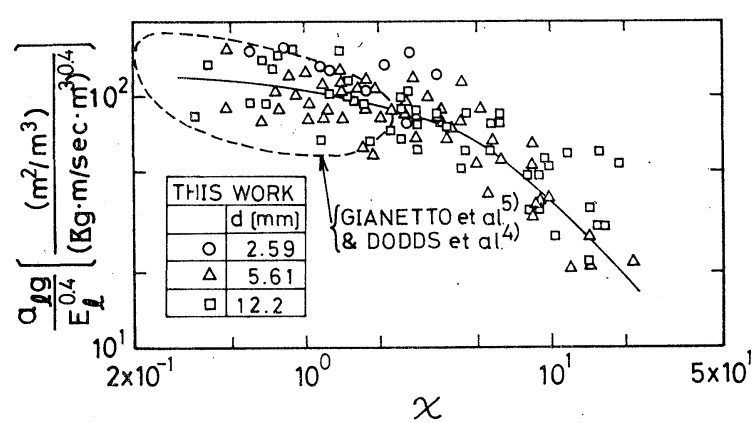

Fig. 7 Alternate correlation of interfacial area in terms of liquid-phase energy loss

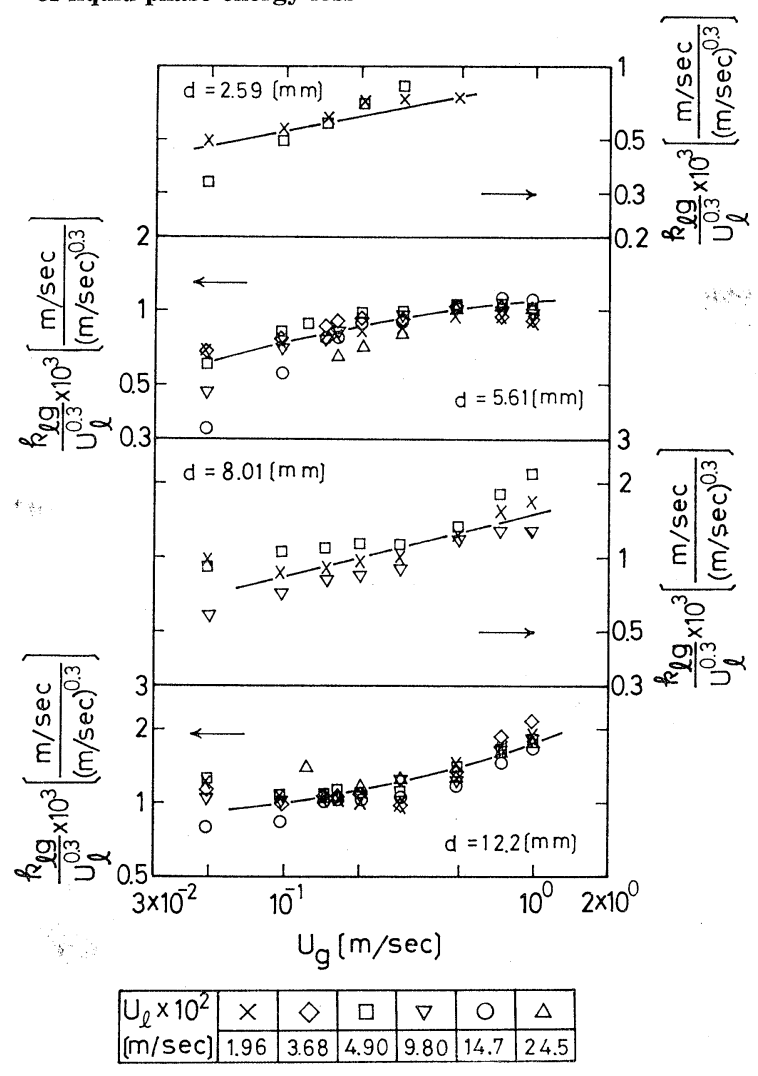

Fig. 8 Results of mass transfer coefficient

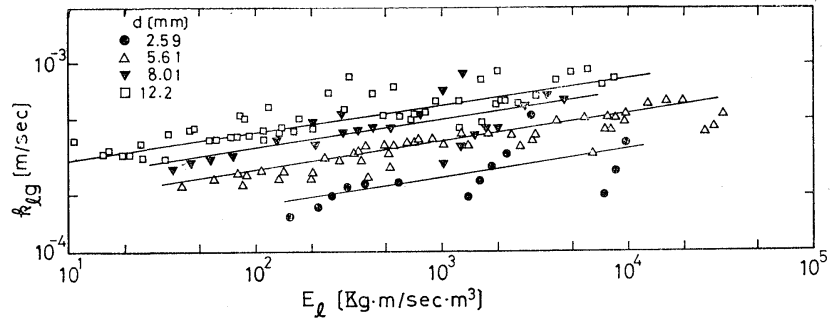

Fig. 9 Correlation of mass transfer coefficient with liquidphase energy loss

given by Eq. (13) into an equation of the penetration theory of gas absorption, one gets

$$
k_{l g} \propto\left(\sqrt{v^{2}} / d_{b}\right)^{1 / 2} \propto E_{l}^{11 / 30}
$$

In Fig. 9, $k_{l g}$ is plotted against $E_{l}$. Although a single correlation is obtained for each packing diameter, it gives lower values of $k_{l g}$ for smaller packing, probably due to the restriction of relative motion between phases mentioned in the preceding paragraph. 


\section{Acknowledgment}

Greatful acknowledgment is made to the Asahi Glass Foundation for Contribution to Industrial Technology for financial support of this project.

$$
\begin{aligned}
& \text { Nomenclature } \\
& a_{l g} \quad=\text { specific interfacial area per unit volume of bed } \\
& a_{s} \quad\left[\mathrm{~m}^{2} / \mathrm{m}^{3}\right] \\
& \text { unit volume of bed }\left[\mathrm{m}^{2} / \mathrm{m}^{3}\right] \\
& C_{l}^{\circ}, C_{l 1}=\text { liquid-phase concentration of } \mathrm{O}_{2} \text { at } \\
& \text { entrance and exit } \quad\left[\mathrm{kg}-\mathrm{mol} / \mathrm{m}^{3}\right] \\
& \bar{C}_{g} \quad=\text { average concentration of } \mathrm{CO}_{2} \quad\left[\mathrm{~kg}-\mathrm{mol} / \mathrm{m}^{3}\right] \\
& \bar{C}_{b} \quad=\text { average concentration of } \mathrm{NaOH} \quad\left[\mathrm{kg}-\mathrm{mol} / \mathrm{m}^{3}\right] \\
& \mathscr{D}=\text { diffusion coefficient of } \mathrm{CO}_{2} \quad\left[\mathrm{~m}^{2} / \mathrm{sec}\right] \\
& d, d_{b} \quad=\text { diameter of packing and bubble }[\mathrm{m}] \\
& E_{l} \quad=\text { liquid-phase energy loss, Eq. (4) } \quad\left[\mathrm{Kg} \cdot \mathrm{m} / \mathrm{sec} \cdot \mathrm{m}^{3}\right] \\
& h \quad=\text { height of packed bed }[\mathrm{m}] \\
& k_{l g} \quad=\text { mass transfer coefficient } \quad[\mathrm{m} / \mathrm{sec}] \\
& k_{r} \quad=\text { reaction rate constant } \quad\left[\mathrm{m}^{3} / \mathrm{sec} \cdot \mathrm{kg}-\mathrm{mol}\right] \\
& (\mathrm{ka})_{l g}=\text { volumetric absorption coefficient }[1 / \mathrm{sec}] \\
& N \quad=\text { absorption rate per unit volume } \\
& \text { of bed } \quad\left[\mathrm{kg}-\mathrm{mol} / \mathrm{sec} \cdot \mathrm{m}^{3}\right] \\
& \Delta P_{g}, \Delta P_{l}=\text { single-phase pressure loss for gas and } \\
& \text { liquid } \\
& {\left[\mathrm{Kg} / \mathrm{m}^{2}\right]} \\
& \Delta P_{l g} \quad=\text { two-phase pressure loss } \\
& R_{l} \quad=\text { liquid holdup per unit void volume } \\
& U_{g}, U_{l}=\text { superficial gas and liquid velocity } \\
& {\left[\mathrm{Kg} / \mathrm{m}^{2}\right]} \\
& \alpha \quad=\text { constant for Eq. (13) } \\
& \varepsilon \quad=\text { void fraction of bed } \\
& \lambda=\text { Ostwald absorption coefficient } \\
& \rho_{c} \quad=\text { density of continuous phase } \\
& \sigma \quad=\text { interfacial tension } \\
& \phi_{l} \quad=\text { two-phase parameter, }=\sqrt{\Delta P_{l g} / \Delta P_{l}} \\
& \chi \quad=\text { two-phase parameter, }=\sqrt{\Delta P_{l} / \Delta P_{g}}
\end{aligned}
$$

\section{Literature Cited}

1) Calderbank, P. H. and M. B. Moo-Young: Chem. Eng.
Sci., 16, 39 (1961)

2) Calderbank, P. H. and A. C. Lochiel: Chem. Eng. Sci., 19, 485 (1964)

3) Cooper, C. M., C. A. Fernstrom and S. A. Miller: Ind. Eng. Chem., 36, 504 (1944)

4) Dodds, W. S., L. F. Stutzman, B. J. Sollami and R. J. McCarter: AIChE J., 6, 197, 390 (1960)

5) Gianetto, A., G. Baldi and V. Specchia: Ing. Chim. Ital., 6, 125 (1970)

6) Gregory, G. A. and D. S. Scott: "Cocurrent Gas-liquid Flow" (Rhodes and Scott ed.) p. 633 (1969)

7) Hartman, M. and R. W. Coughlin: Chem. Eng. Sci., 27, 867 (1972)

8) Hoog, H., L. G. Klinkert and A. Schaafsma: Petrol. Ref., 32, 137 (1953)

9) Hinze, J. O.: AIChE J., 1, 289 (1955)

10) Reiss, L. P.: Ind. Eng. Chem., Proc. Des. Devel., 6, 486 (1967)

11) Rodriguez, F., L. C. Grotz and D. L. Engle: AIChE J., 7, 663 (1961)

12) Sato, Y., T. Hirose, F. Takahashi and M. Toda: J. Chem. Eng. Japan, 6, 147 (1973)

13) Sato, T., T. Hirose, F. Takahashi, M. Toda and Y. Hashiguchi: J. Chem. Eng. Japan, 6, 315 (1973)

14) Satterfield, C. N. and P. F. Way: AIChE J., 18, 305 (1972)

15) Sherwood, T. K. and F. A. L. Holloway: Trans. Am. Inst. Chem. Engrs., 36, 39 (1939)

16) Sylvester, N. D. and P. Pitayagularn: AIChE J., 19, 640 (1973)

17) van Krevelen, D. W. and P. J. Hoftijzer: Chem. Ind. XXI Congr. Int. Chim. Ind., p. 168 (1948)

18) Voyer, R. D. and A. I. Miller: Can. J. Chem. Eng., 46, 335 (1968)

19) Wilke, C. R. and P. Chang: AIChE J., 1, 264 (1955); Wilke, C. R.: Chem. Eng. Progr., 45, 218 (1949)

20) Yoshida, F. and T. Koyanagi: Ind. Eng. Chem., 50, 365 (1958)

21) Yoshida, F., A. Ikeda, S. Imagawa and Y. Miura: Ind. Eng. Chem., 52, 435 (1960)

22) Yoshida, F. and Y. Miura: AIChE J., 9, 331 (1963) 